\title{
UPAYA PENINGKATAN PELAYANAN POSYANDU CITRA SAAT PANDEMI COVID 19 RW 12 DESA JAYARAGA GARUT
}

DOI: https://doi.org/10.33024/jkpm.v4i4.4147

\author{
Udin Rosidin ${ }^{1 *}$, Theresia Eriyani ${ }^{2}$, Ahmad Yamin ${ }^{3}$, Rohmahalia M Noor ${ }^{4}$ \\ 1, 2, 3, Fakultas Keperawatan, Universitas Padjadjaran, \\ ${ }^{4}$ Puskesmas Haurpanggung Garut
}

Disubmit: 10 Maret 2021 Diterima: 17 April 2021 Diterbitkan: 04 Agustus 2021

Email Korespondensi: udin.rosidin@unpad.ac.id

\begin{abstract}
ABSTRAK
Kegiatan PPM ini dilatarbelakangi oleh kejadian pandemi covid 19 yang berdampak kepada pelayanan kesehatan disemua tingkatan, termasuk pelayanan kesehatan di Posyandu Citra RT 04 RW 12 Desa Jayaraga Garut. Pelayanan kesehatan di Posyandu ini tidak bisa melaksanakan pelayanan kesehatan setiap bulan. Ibu yang memiliki bayi balita tidak datang ke posyandu walaupun dijinkan untuk membuka pelayanan selama dua bulan. Melihat kondisi tersebut akan berpengaruh terhadap masalah kesehatan masyarakat. Kegiatan ini bertujuan untuk meningkatkan pelayanan kesehatan di Posyandu Citra saat pandemi Covid 19. Metode kegiatan yang dilaksanakan diawali dengan persiapan sosial, pelaksanaan dan evaluasi kegiatan. Hasil kegiatan PPM ini adalah tetap melakukan pelayanan kesehatan selama dua bulan dan melakukan kunjungan pada bayi balita yang tidak datang dibulan tersebut, melakukan pemeiksaan tekanan darah bagi masyarakat sekitar dan melakukan gerakan kebersihan bersama masyarakat di sekitar lokasi posyandu Citra. Diharapkan dari kegiatan ini dapat meningkatkan peran serta masyarakat dalam bidang kesehatan.
\end{abstract}

Kata Kunci : Covid 19, Peningkatan Pelayanan, Posyandu.

\section{ABSTRACT}

This PPM activity was motivated by the Covid 19 pandemic which had an impact on health services at all levels, including health services at Posyandu Citra RT 04 RW 12 Desa Jayaraga Garut. Health services at this Posyandu cannot provide health services every month. Mothers who have babies under five do not come to the posyandu even though they are allowed to open the service for two months. Seeing this condition will affect public health problems. This activity aims to improve health services at Posyandu Citra during the Covid 19 pandemic. The method of activities carried out begins with social preparation, implementation and evaluation of activities. The results of this PPM activity are continuing to provide 
health services for two months and making visits to infants who do not come this month, conducting blood pressure checks for the surrounding community and conducting hygiene movements with the community around the Posyandu Citra location. It is hoped that this activity can increase community participation in the health sector.

Keywords: Covid 19, Service Improvement, Posyandu.

\section{PENDAHULUAN}

Hidup sehat merupakan hak setiap warga negara Indonesia. Upaya untuk memenuhi hak tersebut pemerintah melaksanakan berbagai tingkat pelayanan kesehatan agar semua warga Indonesia terjangkau oleh pelayanan kesehatan, salah satunya pelayanan posyandu. Posyandu merupakan salah satu bentuk upaya kesehatan besumber daya masyarakat (UKBM) yang dikelola dan diselenggarakan dari, oleh, untuk dan bersama masyarakat. Posyandu terintegrasi dalam penyelenggaraan pembangunan kesehatan, guna memberdayakan masyarakat dan memberikan kemudahan kepada masyarakat dalam memperoleh pelayanan kesehatan dasar untuk mempercepat penurunan angka kematian ibu dan bayi (Kemenkes, 2011).

Kesehatan ibu dan bayi merupakan program prioritas dalam pelayanan kesehatan dasar di posyandu. Semua program posyandu seperti penimbangan berat badan bagi bayi dan balita, pemberian imunisasi dasar, pemeriksaan ibu hamil dan pelayanan keluarga berencana merupakan pelayanan kesehatan ibu serta difokuskan pada kesehatan bayi. Hal ini sesuai dengan Undang-undang Nomor 23 Tahun 2002 tentang perlindungan anak menyatakan bahwa pemerintah wajib memenuhi hak-hak anak, yaitu tentang kelangsungan hidup, pertumbuhan dan perkembangannya serta perlindungan demi kepentingan terbaik anak (Rosidin, Eriyani, \& Sumarna, 2018).

Posyandu merupakan sistem pelayanan kesehatan di masyarakat yang diharapkan dapat menjangkau semua sasaran yang membutuhkan layanan seperti tumbuh kembang anak, ibu hamil, ibu menyusui, dan ibu nifas. Posyandu diasumsikan sebagai salah satu pendekatan yang tepat untuk memantau kesehatan anak. Oleh karena itu posyandu merupakan hal yang penting keberadaannya baik kualitas maupun kuantitas layanan. Untuk mencapai kualitas layanan posyandu diperlukan standarisasi posyandu di semua daerah melalui kegiatan revitalisasi posyandu (Nurhidayah, Hidayati, \& Nuraeni, 2019).

Revitalisasi posyandu ini dititikberatkan pada strategi upaya kesehatan bersumber daya masyarakat menuju kemandirian. Kemandirian dalam pelayanan kesehatan sangat dibutuhkan untuk meningkatkan partisipasi masyarakat. Namun pada umumnya peran posyandu akan menurun apabila posyandu tidak dikelola dengan baik. Pengelolaan posyandu sangat tergantung kepada keaktifan kader kesehatan dan instansi yang membinanya.

Desa Jayaraga merupakan salah satu desa yang memiliki posyandu yang dibina oleh instansi lain sebagai mitra,. Posyandu tersebut adalah posyandu Citra yang berlokasi di RT 04 RW 12. Posyandu Citra merupakan posyandu bentukan PPM dosen Unpad yang diresmikan pada bulan Oktober 2018. Dalam pengelolaannya posyandu 
citra memiliki mitra yaitu Dharma Wanita Pusat Unpad dan Puskesmas Haurpanggung (Rosidin et al., 2018).

Sejalan dengan perkembangan kesehatan masyarakat saat ini. Dimana dunia sedang dilanda wabah pandemi covid 19. Pelayanan kesehatan diberbagai tingkatan mengalami gangguan, termasuk pelayanan kesehatan di posyandu Citra yang tidak bisa memberikan pelayanan setiap bulan. Memperhatikan hal tersebut tim pembina posyandu berinisiatif untuk melakukan beberapa kegiatan sebagai upaya mempertahankan dan meningkatkan pelayanan posyandu dalam membina kesehatan masyarakat. Tujuan kegiatan pengabdian ini adalah untuk meningkatkan pelayanan Posyandu Citra RT 04 RW 12 Desa Jayaraga masa pandemi covid 19.

\section{MASALAH}

Saat pandemi covid 19 melanda dunia seluruh tingkat pelayanan kesehatan banyak terganggu, tidak terkecuali pelayanan di Posyandu Citra. Selama periode bulan September 2020 sampai dengan bulan Februari 2021 pelayanan di posyandu tidak bisa dilaksanakan setiap bulan, dan hanya boleh dilaksanakan dua bulan. Memperhatkan hal tersebut akan berdampak pada kesehatan anak dan kondisi kesehatan lainnya. Selain itu tidak adanya pelayanan kesehatan di posyandu akan berdampak pula pada peran serta masyarakat. Kehadiran ibu yang memiliki bayi balita merasa khawatir untuk datang ke posyandu. Peran serta masyarakat secara keseluruhan juga akan berkurang apabila pelayanan di Posyandu Citra ditiadakan. Untuk mempertahankan agar peran posyandu tidak berhenti berbagai strategi terus diupayakan. Strategi tersebut diantaranya pelayanan kesehatan di posyandu dilaksanakan pada bulan September dan Oktober 2020 sesuai dengan kebijakan pemerintah daerah Kabupaten Garut. Bagi yang tidak hadir pada dua bulan tersebut diusahakan dapat dikunjungi kader kesehatan untuk menimbang berat badan anak sekaligus memberikan makanan tambahan (PMT) kepada bayi dan balta yang dikunjungi. Kegiatan lainnya adalan melakukan pemeriksaan tekanan darah kepada masyarakar yang tinggal di sekitar posyandu dan melakukan gerakan kebersihan di lingkungan posyandu. Diharapkan program ini dapat mempertahan pelayanan posyandu di RT 04 RW 12 Desa Jayaraga yang berhenti karena adanya pandemi Covid 19. 


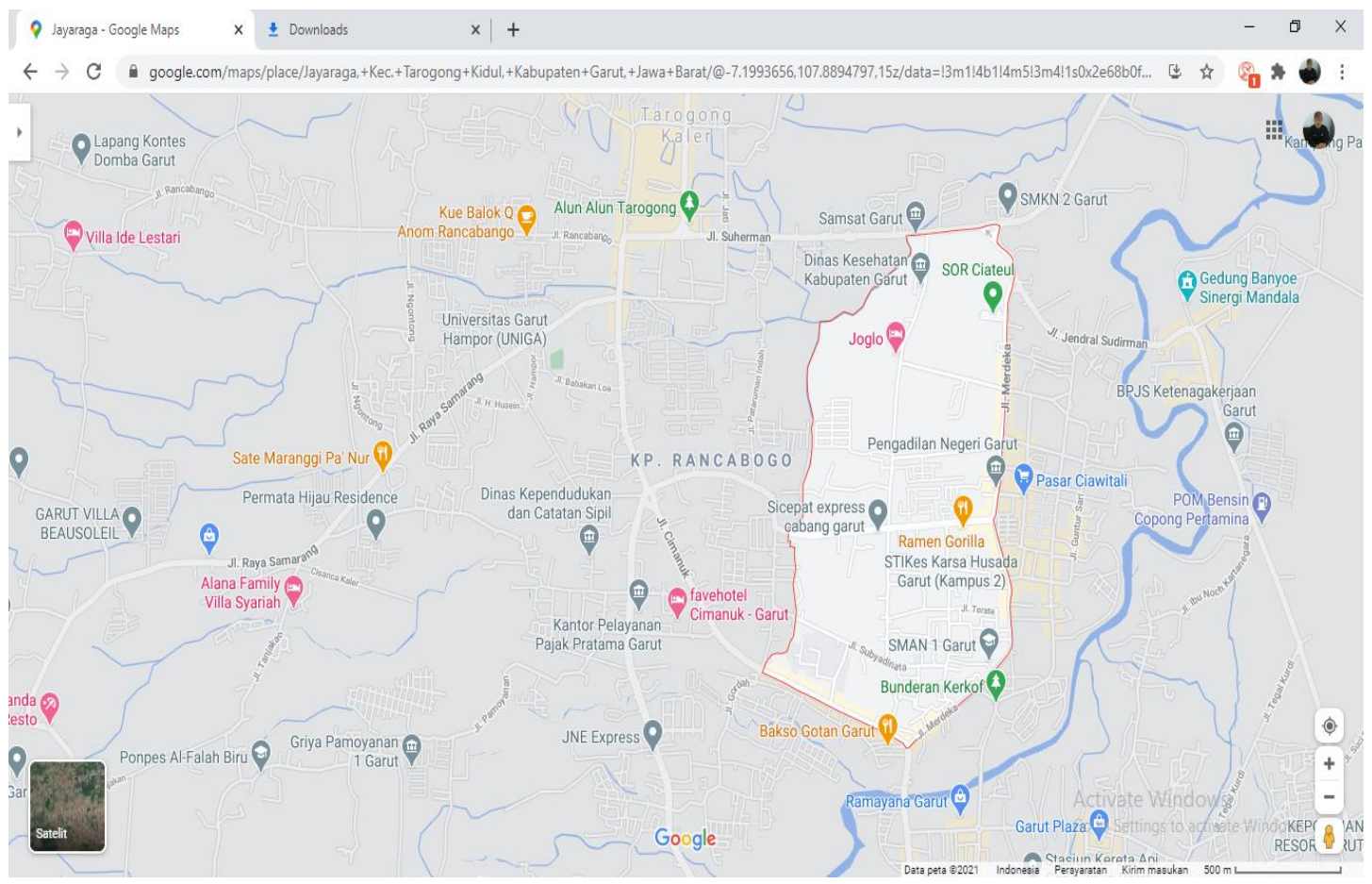

Gambar 2.1 Peta Lokasi RT 04 RW 12 Desa Jayaraga Garut

\section{METODE}

Kegiatan PPM dilaksanakan melalui beberapa tahapan, pertama persiapan sosial kemudian tahap pelaksanaan dan tahap evaluasi. Tahap persiapan sosial dilaksanakan sebelum kegiatan PPM dimulai. Tim PPM terlebih dahulu mengadakan pertemuan dengan Ketua RW 12, Kepala Puskesmas Haurpanggung dan Kepala Desa Jayaraga. Pada tahap ini dibahas berbagai kebijakan Pemerintah Daerah Kabupaten Garut tentang pelayanan posyandu pada saat pandemi covid 19. Karena pelayanan posyandu tidak bisa dibuka setiap bulan maka disepakati beberapa kegiatan agar posyandu Citra tetap memiliki peran dalam pembangunan kesehatan di RT 04 RW 12 Desa Jayaraga. Hasil persiapan awal disepakati beberapa kegiatan yang akan dilaksanakan seperti pelayanan posyandu dilaksanakan bulan September dan Nopember 2020 sesuai kebijakan pemerintah daerah. Kader kesehatan mengunjungi bayi balita yang tidak datang ke Posyandu Citra pada dua bulan tersebut. Kemudian pada pelayanan tersebut dilakukan pula pelayanan pemeriksaan tekanan darah untuk mendeteksi resiko penyakit tidak menular (PTM) khususnya resiko penyakit hipertensi. Selain pelayanan kesehatan disepakati pula kegiatan kebersihan lingkungan di posyandu. Tahap pelaksanakan dan evaluasi kegiatan melibatkan semua kader kesehatan dan masyarakat RW 12 Desa Jayaraga, Jajaran Pemerintah Desa Jayaraga dan Puskemas Haurpanggung. 


\section{HASIL PEMBAHASAN}

Kegiatan pengabdian pada masyarakat ini dilaksanakan pada periode September 2020 sampai dengan Februari 2021. Sesuai dengan kesepakatan para pembina dan mitra Posyandu Citra dengan mempertimbangkan kebijakan pemerintah daerah bahwa kegiatan pelayanan posyandu hanya dilaksanakan dua kali, yaitu bulan September 2020 dan Oktober 2020. Kemudian pada bulan bulan berikutnya atas inisiatip tokoh masyarakat kegiatan pengabdian pada masyarakat difokuskan pada kegiatan bersama masyarakat yaitu kerja bakti di lingkungan posyandu. Untuk pelayanan posyandu dilaksanakan pada minggu kedua setiap bulannya.
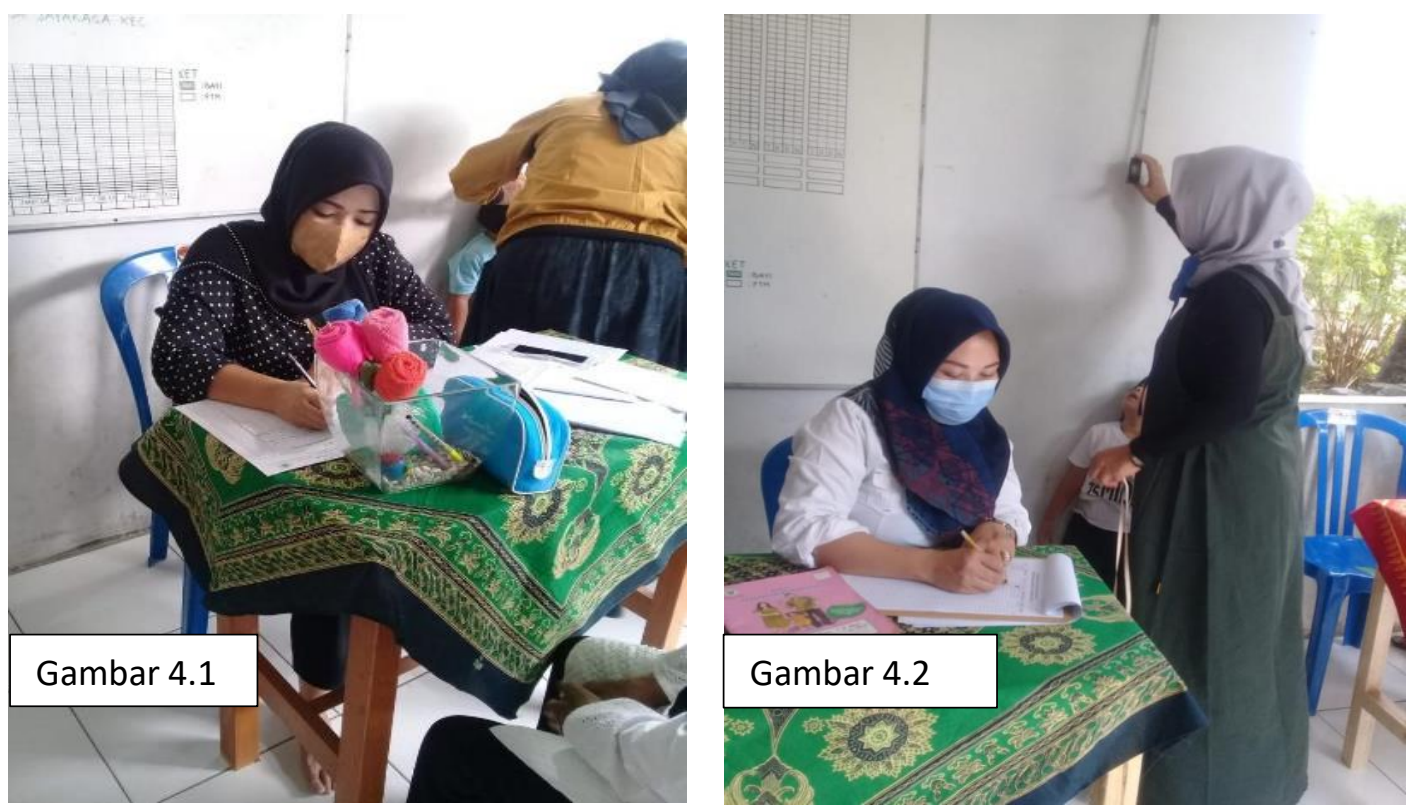

Gambar 4.1 dan 4.2 Pelayanan Posyandu Citra bulan September 2020 dan Oktober 2020 di RT 04 RW 12 Desa Jayaraga Garut

Kunjungan bayi/balita pada bulan September dan Oktober 2020 hanya dikunjungi oleh sebagian kecil bayi balita yang ada. Rendahnya kunjungan tersebut diakibatkan oleh kekhawatiran ibu atau keluarga untuk membawa anaknya ke posyandu. Kekhawatiran tersebut sangat menggangu motivasi ibu untuk membawa anaknya ke posyandu. Menurut penelitian (Yani, Rosidin, \& Harun, 2020) menunjukkan bahwa motivasi sangat berpengaruh terhadap kunjungan ibu ke posyandu untuk mendapatkan pelayanan imunisasi dasar. Semakin baik motivasi responden maka akan semakin baik perilaku ibu yang memiliki bayi balita untuk datang ke posyandu. Penelitian lain menunjukkan bahwa ada hubungan yang bermakna antara persepsi dengan perilaku ibu membawa balita ke posyandu. Motivasi merupakan dimensi persepsi paling besar yang mendorong ibu untuk membawa balita ke posyandu (Kusuma, Sari, \& Nurhidayah, 2015)

Motivasi sangat menentukan perilaku ibu untuk datang ke posyandu karena motivasi adalah keinginan yang terdapat pada diri seseorang individu yang mendorongnya untuk melakukan perbuatan-perbuatan, tindakan, tingkah laku atau perilaku. Jadi motivasi itu merupakan suatu dorongan yang timbul adanya 
rangsangan-rangsangan dari dalam maupun luar sehingga seseorang berkeinginan untuk mengadakan perubahan tingkah laku atau aktivitas tertentu lebih baik dari keadaan sebelumnya (Nurdin, Ediana, \& Ningsih, 2019).

Menurunnya kunjungan bayi dan balita di RT 04 RW 12 Desa Jayaraga saat pandemi covid 19 dimungkinkan karena menurunnya motivasi eksternal dari orang tuanya. Kekhawatiran tentang penularan covid 19 menjadi faktor utama turunnya motivasi ibu untuk datang ke posyandu. Pemahaman yang baik tentang pencegahan covid 19 berdampak pada turunya motivasi eksternal ibu untuk datang ke posyandu. Hal tersebut sangat dimaklumi karena pencegahan covid 19 merupakan hal yang utama untuk diperhatikan. Upaya untuk tetap bisa memantau kesehatan anak bayi dan balita maka dilakukan kunjungan oleh kader kesehatan kepada bayi dan balita yang tidak datang ke posyandu saat itu. Kader kesehatana datang membawa timbangan dan memberikan makanan tambahan (PMT) karena bayi dan balita tidak datang ke posyandu dengan alasan pencegahan covid 19.

Program kunjungan kader kesehatan ke ibu yang memiliki anak bayi dan balita merupakan gagasan dari mitra posyandu Citra. Karena program ini merupakan program yang situasional saat pandemi covid 19 maka mayarakat belum mengetahui adanya kegiatan tersebut. Sehingga pada saat kunjungan kader kesehatan tersebut banyak ibu yang menolak dengan berbagai alasan. Keberhasilan program ini tidak maksimal karena tidak adanya sosialisasi kepada masyarakat terlebih dahulu. Sosialisasi sangat berpengaruh terhadap keberhasilan suatu program (Aprillia, 2010).

Selain pelayanaan bayi dan balita pada bulan tersebut dibuka juga pelayanan pemeriksaan tekanan darah bagi masyarakat yang tinggal disekitar posyandu. Pemeriksaan ini bertujuan untuk menjaring resiko terjadinya penyakit tidak menular (PTM) khususnya resiko penyakit hipertensi pada masyarakat RT 04 RW 12 Desa Jayaraga Kecamatan Tarogong Kidul Kabupaten Garut.
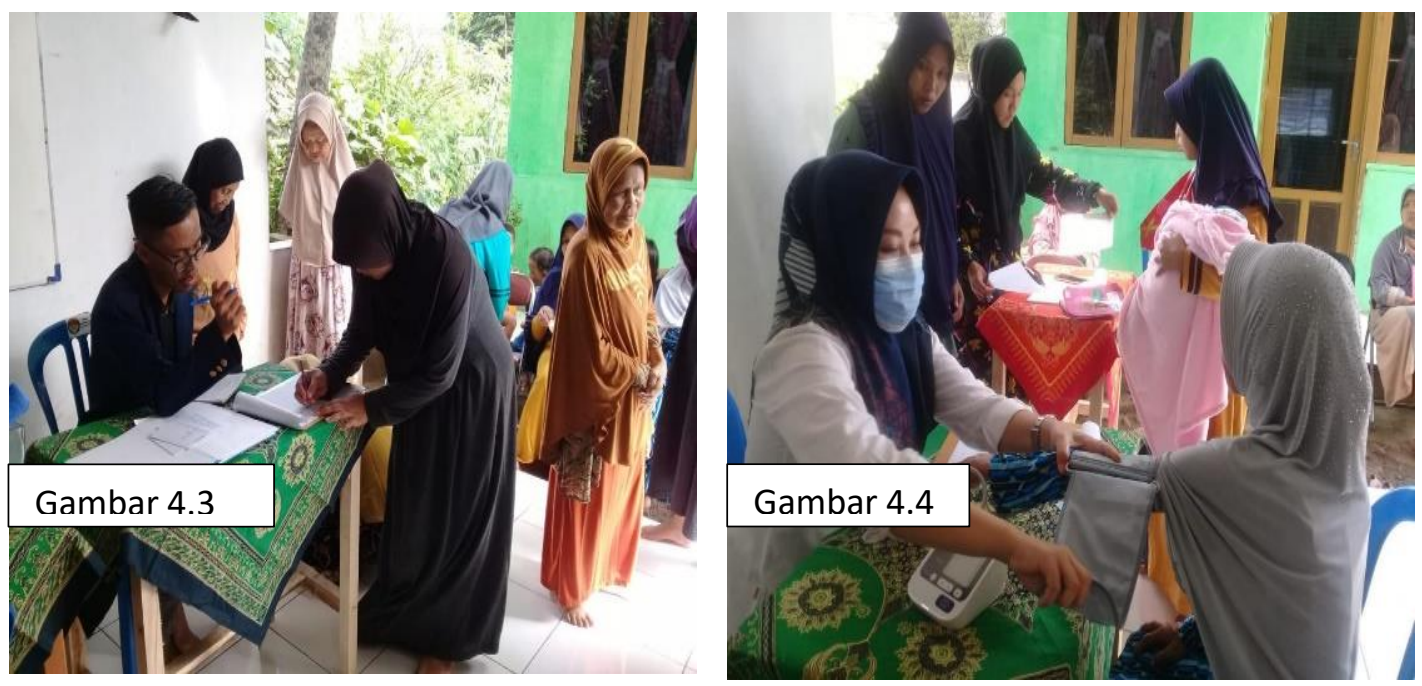

Gambar 4.3 dan 4.4 Kegiatan Pelayanan Pemeriksaan Tekanan Darah pada Masyarakat RT 04 RW 12 Desa Jayaraga Garut 
Kegiatan pemeriksaan kesehatan dalam hal ini pemeriksaan tekanan darah merupakan upaya agar masyarakat mau melaksanakan hidup sehat dalam pencegahan penyakit hipertensi. Tim PPM melaksanakan kegiatan ini diharapkan dapat menjadi deteksi dini bagi masyarakat yang memiliki risiko terjangkit penyakit hipertensi. Dengan dilakukannya pemeriksaan tekanan darah maka masyarakat akan memahami kondisi kesehatannya, sehingga masyarakat bisa mengatur hidupnya menuju perilaku hidup sehat. Pencegahan yang perlu dilakukan untuk mencegah hipertensi adalah menerapkan gaya hidup sehat (Rosidin, Witdiawati, \& Sumarna, 2020). Menurut (Junita, Handayani, \& Alfiah, 2020) Gerakan masyarakat hidup sehat merupakan upaya untuk meningkatkan kesadaran, kemauan dan kemampuan bagi setiap orang untuk hidup sehat agar peningkatan derajat kesehatan masyarakat yang setinggi-tingginya dapat terwujud. Tujuan umum gerakan masyarakat hidup sehat, a) Perubahan gaya hidup lebih baik dan b) Meningkatnya peran masyarakat dalam memanfaatkan fasilitas kesehatan. Kegiatan ini dimanfaatkan oleh 21 orang warga masyarakat yang tinggal dilingkungan posyandu. Selain itu program ini merupakan informasi awal dalam pengembangan posbindu di RT 04 RW 12 Desa Jayaraga Garut.

Dasar kegiatan pemeriksaan tekanan darah bagi masyarakat RW 12 Desa Jayaraga adalah kurangnya pemahaman masyarakat tentang penyakit hipertensi. Hipertensi juga merupakan penyakit yang sering dijumpai di masyarakat dengan jumlah penderita yang terus meningkat setiap tahunnya (Situmorang, 2015). Tidak sedikit masyarakat yang memiliki resiko penyakit hipertensi tanpa menyadarinya. Hipertensi sering disebut sebagai Silent Killer, karena hipertensi merupakan penyakit yang mematikan tanpa disertai adanya gejala terlebih dahulu. Karena tidak menunjukkan gejala tersebut sering kali masyarakat merasa aman dan sehat serta berpikiran tidak memiliki resiko terhadap penyakit tersebut.

Menurut penelitian yang dilakukan oleh (Anggara \& Prayitno, 2013) menunjukkan bahwa untuk mengurangi kasus hipertensi perlu adanya upaya untuk mencegahnya seperti melakukan pemeriksaan tekanan darah secara rutin. Penelitian lain menunjukkan bahwa upaya pencegahan hipertensi adlah melalui program CERDIK terdiri dari Cek Kesehatan secara berkala, Enyahkan asap rokok, Rajin Olahraga, Diet, Istirahat yang cukup dan Kelola stress. Cek kesehatan berkala dalam hal ini adalah mengukur tekanan darah. Mengukur tekanan darah diperlukan pada pasien hipertensi untuk mengontrol tekanan darah secara berkala serta dapat mendeteksi awal risiko komplikasi hipertensi (Pambudi \& Khusna, 2019). Dengan diperkenalkan kepada masyarakat RW 12 Desa Jayaraga tentang pentingnya pemeriksaan tekanan darah maka diharapkan setiap warga masyarakat bisa melaksanakan hidup sehat dengan cara melaksanakan upaya pencegahan penyakit hipertensi.

Kegiatan lainnya yang dilakukan tim Pengabdian pada Masyarakat (PPM) adalah melakukan kerja bakti, yaitu suatu gerakan kebersihan bersama masyarakat di lingkungan sekitar posyandu. Kegiatan ini diprakarsai oleh kepala Desa Jayaraga dalam rangka memaksimalkan peran serta masyarakat dalam pembangunan kesehatan di Desa Jayaraga. Pertimbangan lain dari gerakan kebersihan ini karena mulai bulan Nopember 2020 tidak diijikan adanya pelayanan kesehatan di posyandu. Gerakan kebersihan ini diikuti oleh kader kesehatan RW 12, tokoh masyarakat, kepala Desa Jayaraga beserta jajarannya, Kepala Puskesmas Haurpanggung dan beberapa staf serta tim pengabdian masyarakat. Kegiatan dilaksanakan pada hari Jumat tanggal 20 Nopember 2020 jam 08.00 sampai dengan jam 10.00 WIB. 

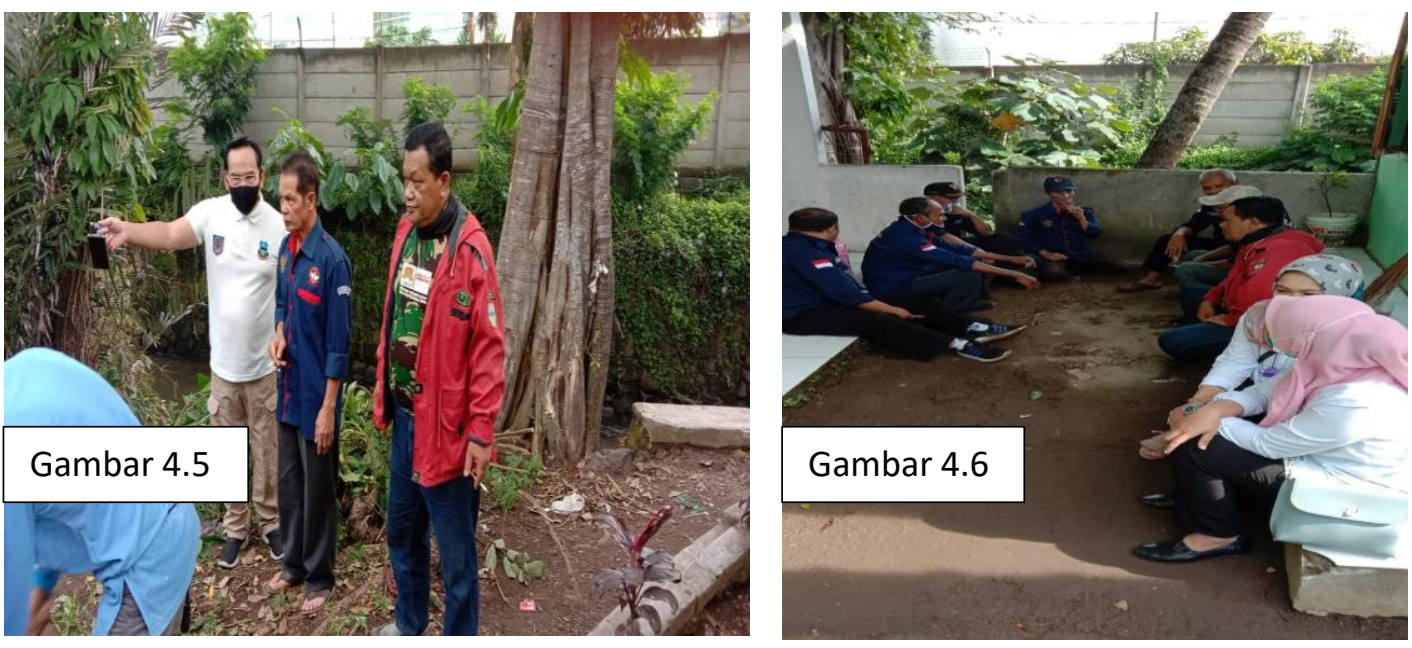

Gambar 4.5 dan 4.6 Kepala Desa Jayaraga dan para Tokoh Masyarakat sedang Melaksanakan kegiatan Kebersihan Linkungan Posyandu Citra RT 04 RW 12 Desa Jayaraga Garut

Peningkatan peran serta masyarakat dalam bidang kesehatan perlu terus dilakukan. Gerakan kebersihan bersama masyarakat merupakan upaya peningkatan peran serta masyarakat dalam bidang kesehatan. Gerakan ini dimaksudkan agar masyarakat memiliki kepedulian terhadap fasilitas pelayanan kesehatan yang ada. Gerakan kebersihan ini merupakan pola untuk membiasakan dan memberdayakan masyarakat dalam pembangunan kesehatan di lingkungannya. Kebiasaan yang baik dalam kesehatan akan menjadi faktor predisposisi untuk perilaku hidup bersi dan sehat. Menurut (Notoatmodjo, 2014) Perilaku kesehatan akan dipengaruhi oleh tiga faktor yaitu faktor predisposisi berupa pengetahuan, sikap, kebiasaan dan nilai nilai yang dianut. Fektor kedua yatu enabling berupa sarana dan fasilitas dan faktor ketiga yaitu reinforcing atau faktor penguat bisa berbentuk sikap tokoh masyarakat atau sikap petugas kesehatan dan kebijakan lainnya.

Pemberdayaan masyarakat dalam bidang kesehatan sangat diperlukan terutama yang berkaitan dengan aspek sosial budaya. Salah satu cara yang dinilai akan mempercepat keberhasilan suatu kegiatan adalah dengan menggunakan pendekatan pemberdayaan masyarakat. Suatu kegiatan dapat dikategorikan sebagai pemberdayaan bila mampu memperkuat, meningkatkan atau mengembangkan potensi masyarakat setempat (Dwiyanto, 2011). Gerakan kebersihan lingkungan yang dilaksanakan dalam kegiatan pengabdian pada masyarakat ini diharapkan dapat menjadi wahana untuk mengembangkan potensi masyarakat RT 04 RW 12 Desa Jayaraga Garut. Upaya mengembangkan potensi masyarakat dalam bidang kesehatan melalui kegiatan yang melibatkan masyarakat harus terus dilakukan oleh semua dinas instansi bidang kesehatan. Karena menurut Ascobat Gani dalam (Dwiyanto, 2011) mengemukakan bahwa peran serta masyarakat masih terbatas pada fase sekedar terlibat dan menjadi bagian dari kegiatan. Melalui kegiatan pengabdian ini diharapkan dapat meningkatkan peran serta masyarakat dalam bidang kesehatan khususnya dalam pelayanan kesehatan di Posyandu Citra RT 04 RW 12 Desa Jayaraga Kabupaten Garut. 


\section{KESIMPULAN}

Kegiatan pengabdian pada masyarakat periode ini terjadi saat pandemi covid 19 sedang melanda dunia. Oleh karena itu kegiatan PPM diarahkan untuk mencoba mencari strategi yang bisa dilaksanakan dengan tetap memeliharan peran posyandu dalam pelayanan kesehatan kepada masyarakat. Upaya peningkataan pelayanan Posyandu Citra di RT 04 RW 12 Desa jayaraga Kabupaten Garut adalah ; a) Tetap memberikan pelayanan kesehatan kepada bayi dan balita selama dua bulan dan dilakukan kunjungan oleh kader kesehatan kepada bayi dan balita yang tidak datang ke posyandu; b) Memberikan pelayanan pemeriksaan tekanan darah kepada masyarakat sekitar sebagai upaya penjaringan penyakit tidak menular (PTM) dan c) Melaksanakan gerakan kebersihan di lingkungan Posyandu Citra sebagai upaya untuk memberdayakan masyarakat dalam bidang kesehatan.

\section{DAFTAR PUSTAKA}

Anggara, F. H. D., \& Prayitno, N. (2013). Faktor-Faktor Yang Berhubungan Dengan Tekanan Darah Di Puskesmas Telaga Murni, Cikarang Barat Tahun 2012. Jurnal Ilmiah Kesehatan, 5(1), 20-25.

Junita, E., Handayani, Y., \& Alfiah, L. N. (2020). Germas (Gerakan Masyarakat Hidup Sehat) Di Desa Rambah Hilir. Kumawula: Jurnal Pengabdian Kepada Masyarakat, 3(1), 100-105.

Kemenkes, R. I. (2011). Pedoman Umum Pengelolaan Posyandu. Kemenkes Ri. Jakarta: Kelompok Kerja Operasional Posyandu.

Kusuma, D. P., Sari, S. P., \& Nurhidayah, I. (2015). Hubungan Persepsi Dengan Perilaku Ibu Membawa Balita Ke Posyandu. Jurnal Keperawatan Padjadjaran, $3(1)$.

Notoatmodjo, S. (2014). Promosi Kesehatan Dan Perilkau Kesehatan. Jakarta: Rineka Cipta.

Nurdin, N., Ediana, D., \& Ningsih, N. S. D. M. (2019). Faktor-Faktor Yang Berhubungan Dengan Partisipasi Ibu Balita Ke Posyandu Di Jorong Tarantang. Jurnal Endurance: Kajian Ilmiah Problema Kesehatan, 4(2), 220-234.

Nurhidayah, I., Hidayati, N. O., \& Nuraeni, A. (2019). Revitalisasi Posyandu Melalui Pemberdayaan Kader Kesehatan. Media Karya Kesehatan, 2(2).

Pambudi, R. S., \& Khusna, K. (2019). Tingkat Pengetahuan Program Cerdik Dan Informasi Obat Pada Pasien Hipertensi Di Puskesmas X Surakarta. Pharmed: Journal Of Pharmaceutical Science And Medical Research, 2(2), 69-76.

Rosidin, U., Eriyani, T., \& Sumarna, U. (2018). Pembentukan Pelayanan Posyandu Citra Rt 4/12 Kampung Jembatan Baru Desa Jayaraga Tarogong Kidul Garut. Jurnal Pengabdian Kepada Masyarakat, 2(5), 341-398.

Rosidin, U., Witdiawati, W., \& Sumarna, U. (2020). Beraksi Cegah Penyakit Tidak Menular Di Rw 2 Kelurahan Jayawaras Tarogong Kidul Garut. Kumawula: Jurnal Pengabdian Kepada Masyarakat, 3(3), 507-514.

Situmorang, P. R. (2015). Faktor-Faktor Yang Berhubungan Dengan Kejadian Hipertensi Pada Penderita Rawat Inap Di Rumah Sakit Umum Sari Mutiara Medan Tahun 2014. Jurnal Ilmiah Keperawatan Imelda, 1(1), 71-74.

Yani, Y., Rosidin, U., \& Harun, H. (2020). Determinan Perilaku Ibu Membawa Anaknya Mendapatkan Imunisasi Dasar Lengkap Di Puskesmas Cibiuk. Jurnal Keperawatan Bsi, 8(1), 68-79. 